ence now of such differentials in societies with very different social structures to those of Britain today. When Chapin documented mortality differentials in Providence in 1924 he hoped that such a demonstration would be preparation for "what should be of great value, namely a study of the habits of life and environment which make for the longevity of the well-to-do." ${ }^{28}$ This still pertains.

The authors acknowledge the generous assistance of David Crawshaw, cemeteries and crematoria officer and registrar, Glasgow City Council, and the technical support of David Bell and Moira Willison of Glasgow Polytechnic.

1 Chadwick E. Report on the sanitary condition of the labouring population of Grea Britain, 1842. Edinburgh: Edinburgh University Press, 1965.

2 Inter-Departmental Committee on Physical Deterioration. Report. London: HMSO, 1904

3 Stevenson THC. The social distribution of mortality from different causes in England and Wales, 1910-12. Biometrika 1923;15:382-400.

4 Stevenson THC. The vital statistics of wealth and poverty. Fournal of the Royal Statistical Society 1928;91:207-20.

5 Pamuk ER. Social class inequality in mortality from 1921 to 1972 in England and Wales. Population Studies 1985;39:17-31.

6 Stocks $P$. The effects of occupation and of its accompanying environment on mortality. Fournal of the Royal Statistical Society 1938;101:669-708.

Logan WPD. Social class variations in mortality. $\mathrm{Br} f$ Prev Soc Med 1954;8:128-37.

8 Hart JT. Data on occupational mortality, 1959-63: too little and too late. Lancet 1972;i:192-3.

9 Morris JN. Social inequalities undiminished. Lancet 1979;i:87-90.
10 Blane D, Davey Smith G, Bartley M. Social class differences in years of potential life lost: size, trends and principal causes. BMF 1990;301:429-32.

11 Davey Smith G, Bartley M, Blane D. The Black report on socioeconomic Davey Smith G, Bartley M, Blane D. The Black report
inequalities in health: 10 years on. BMF 1990;301:373-7.

inequalities in health: 10 years on. BMF 1990;301:373-7.
12 Fox J, Goldblatt PO. Longitudinal study: socio-demographic mortality differentials. London: HMSO, 1982.

13 Davey Smith G, Shipley MJ, Ruse G. The magnitude and causes of socioeconomic differentials in mortality: further evidence from the Whitehall economic differentials in mortality: further evidence
study. $\mathcal{F}$ Epidemiol Community Health 1990;44:265-70.

14 Willing JA, Fairie JS. Burial grounds of Glasgow: a brief guide for genealogists. Glasgow: Glasgow and West of Scotland Family History Society, 1986.

15 Spon's architects' and builders' price book. London: Spon, 1990.

16 Jannerfeldt E, Horte L-G. Median age at death as an indicator of premature mortality. BMF 1986;296:678-81.

17 Thirty-sixth detailed annual report of the Registrar-General of births, deaths and marriages in Scotland. Edinburgh: HMSO, 1892.

18 Best G. Mid-Victorian Britain 1851-1875. London: Fontana, 1979.

19 Titmuss R. Birth, poverty and wealth. London: Hamish Hamilton Medical Books, 1943.

20 Morris JN. Uses of epidemiology. London: Livingstone, 1957.

21 Antonovsky A. Social class, life expectancy and overall mortality. Milbank Memorial Fund Quarterly 1967;45:31-73.

22 Booth C. Charles Booth's London: a portrait of the poor at the turn of the century. London: Hutchinson, 1969.

23 Moser K, Pugh H, Goldblatt P. Mortality and the social classification of women. In: Goldblatt P, ed. Longitudinal study: mortality and social organisation. London: HMSO,

24 Goldblatt P. Mortality and alternative social classifications. In: Longitudinal study: mortality and social organisation. London: HMSO, 1990:163-92.

25 Checkland O, Lamb M, eds. Bibliography. In: Health care as social history: the Glasgow case. Aberdeen: Aberdeen University Press, 1982.

26 Davey Smith G, Egger M. Socioeconomic differences in mortality in Britain and the United States. Am f Public Health 1992;82:1079-81.

27 Morrison AS, Kirshner J, Molho A. Life cycle events in 15th century Florence: records of the Monte Delle Doti. Am J Epidemiol 1977;106: 487-92.

28 Chapin CV. Deaths among taxpayers and non-taxpayers of income tax, Providence, 1865. Am F Public Health 1924;14:647-51.

\title{
The transformation of maternal mortality
}

\section{Irvine Loudon}

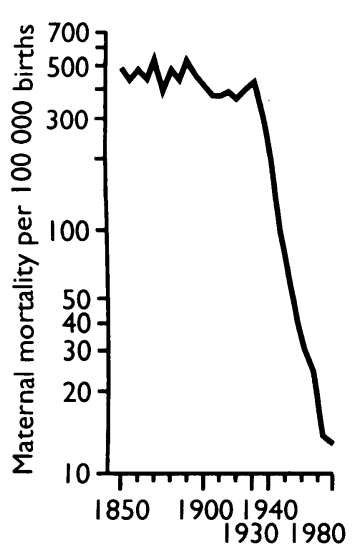

FIG 1-Maternal mortality, quinquennial averages 1850-1980. Logarithmic scale

Wantage, Oxfordshire OX12 9EH

Irvine Loudon, medical historian

BMf 1992;305:1557-60
There can be no doubt that the most remarkable feature of childbirth in this century is the profound decline in maternal deaths throughout the Western world. From 1900 to 1935 the average maternal mortality in England and Wales was around 400 per 100000 births, with the lowest rate of 355 in 1910 and the highest, 441, in 1934. From 1935, however, there was a dramatic change. Maternal mortality began its steep and sustained decline until, by the 1980 s, it had fallen to less than nine deaths per 100000 births: roughly one fiftieth of the rate in $1934 .^{1}$

Figure 1 shows these features: the plateau of maternal mortality followed by the steep and continuous fall. A broadly similar trend-a plateau and a steep decline-was seen in all Western countries. During the period from 1900 to 1935 , however, there were striking differences in national levels of maternal

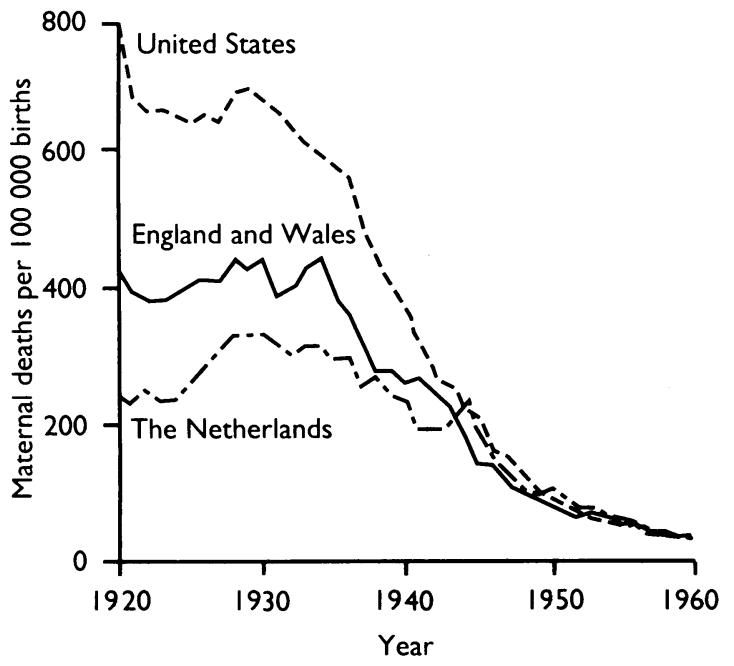

FIG 2-Annual trends in maternal mortality expressed as maternal deaths per 100000 births mortality (table I, figure 2). The United States had the highest level of maternal mortality, the Netherlands and Scandinavia the lowest; England and Wales occupied an intermediate position. Only a small part of international differences could be attributed to statistical methodology. When these were eliminated, the rank order shown in table I remained intact.

TABLE I-Maternal mortality in certain countries in $1920 .{ }^{25}$

\begin{tabular}{lc}
\hline Country & $\begin{array}{c}\text { Maternal mortality from all } \\
\text { causes (per 100 000 live births) }\end{array}$ \\
\hline Denmark & 235 \\
The Netherlands & 242 \\
Sweden & 258 \\
Norway & 297 \\
Finland & 360 \\
England and Wales & 433 \\
Australia & 501 \\
Ireland & 553 \\
Belgium & 609 \\
Scotland & 615 \\
New Zealand & 648 \\
France & 664 \\
United States & 689
\end{tabular}

$\star 1918 .+1919$.

Why were there such wide differences between Western countries? Why was it so much safer in the 1920s to have a baby in the Netherlands than the United States? And why, as we will see, had these wide differences virtually disappeared by 1960 ? It might be thought that the answer lay in social and economic differences, on the assumption that rates of maternal mortality were primarily determined by factors such as poverty and malnutrition - but this was not the answer. Maternal mortality, unlike infant mortality, was remarkably insensitive to social and economic factors per se but remarkably sensitive to standards of obstetric care. ${ }^{34} \mathrm{I}$ believe that the answers to the questions asked above will be found in international comparisons of maternal policies and systems of maternal care. I have 
chosen to compare Britain, the United States, and north west Europe.

\section{Britain}

Although William Farr, compiler of abstracts at the General Register Office, had recognised in the 1870s that maternal mortality was too high and that many maternal deaths were preventable, ${ }^{56}$ it was not until the 1920 s that the significance of the high and undiminishing level of maternal mortality was fully appreciated. Maternal mortality ought to have declined in line with the decline in infant mortality, but against al expectations maternal mortality began to rise after the low level recorded in 1910. Following the first world war, the 1920s became the formative decade for policies on maternal care designed to reduce the scandalous loss of young women in the prime of life and the devastating effects on families when the mother dies in childbirth. ${ }^{4}$

It was always assumed that the maternity services should be built on a solid foundation of home deliveries by midwives and general practitioners. There was only a small number of maternity beds (many, in fact, were under the control of general practitioners) and an even smaller number of trained obstetricians, for the College of Obstetricians and Gynaecologists was not established until 1929. Hospital delivery for every woman was neither feasible nor, with the ever present danger of cross infection, desirable. Maternity hospitals staffed by specialists were largely restricted to "social admissions," high risk cases, and emergencies.

General practitioners supported such a policy, believing that midwifery was an integral part of general practice rather than a specialty. They had no intention of abandoning their belief that midwifery was the linchpin of general practice. ${ }^{7}$ As far as midwives were concerned, Britain, in comparison to the rest of Europe, was late in introducing compulsory training and regulation: the first Midwives Act was passed only in 1902; others followed in 1918 and 1936. By the $1930 \mathrm{~s}$ these had ensured the future of the midwife and transformed the standard of care, but the process was slow.

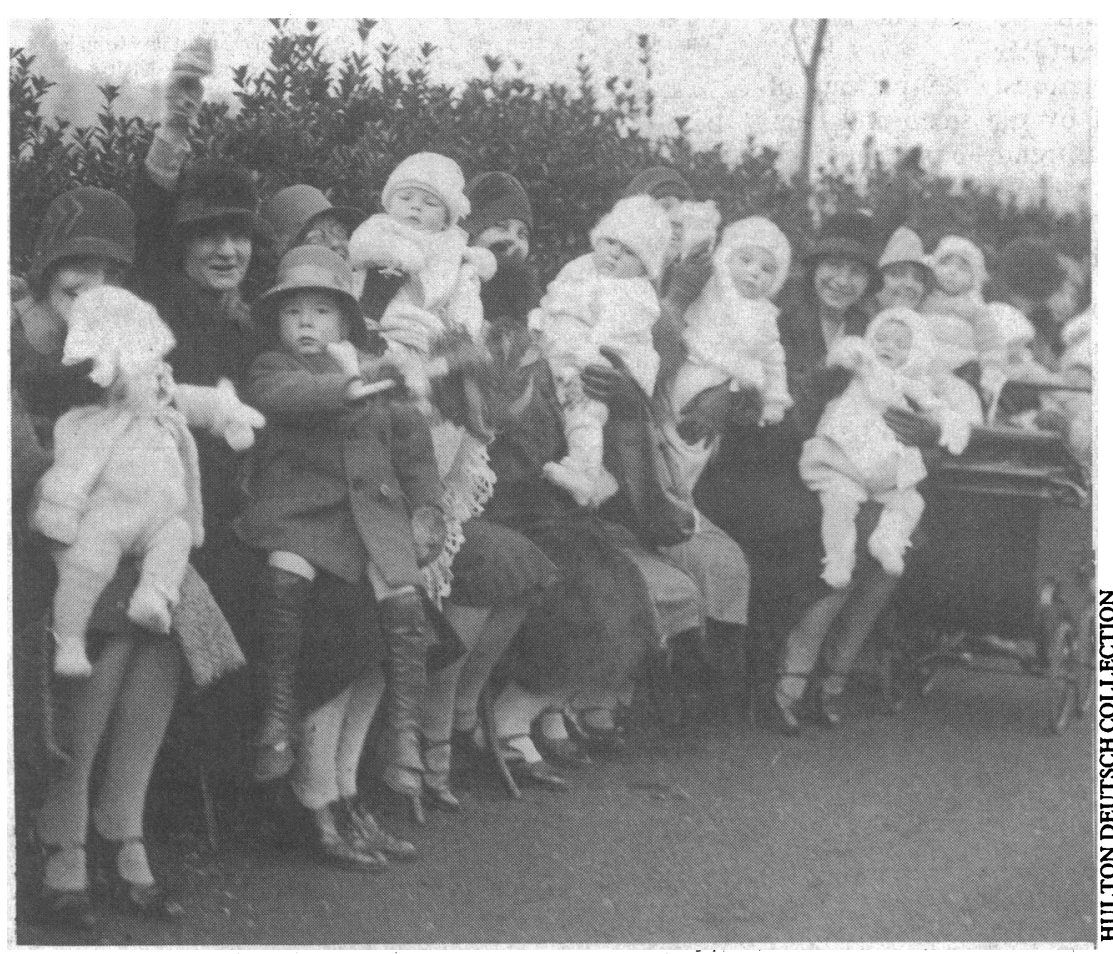

In the interwar period maternal care in Britain was split between midwives, general practitioners, medical officers of health, and specialist obstetricians. The average maternal mortality was about four women per 1000 births until 1935, when it began a steep decline
Against a background of maternal care split between midwives, general practitioners, medical officers of health, and specialist obstetricians, the outstanding feature of maternal care in Britain during the interwar period was a degree of disparity that almost defies description. Midwives ranged from untrained handywomen, who persisted until the second world war, through the "bona fides" midwives (untrained midwives who were in practice before 1902 and were registered under the provisions of the 1902 act if judged respectable and reliable), to fully trained modern midwives, the best of whom, such as the Queen's Institute nurse-midwives, provided an exceptionally high standard of care and achieved a very low rate of maternal mortality.

General practitioners, too, varied enormously. Many were careful, skilled, and conscientious; other used forceps and chloroform on every possible occasion. "We did approximately 250 cases a year," said Dr Finer, writing of general practice in 1931, "mostly with chloroform and forceps and my principal said that it allowed us to get a bed quicker". (Dr J Finer, Chigwell, Essex personal communication, 1990). Chloroform and forceps, said general practitioners, were what patients demanded and there wasn't time to wait. Often, the techniques of antisepsis and asepsis were grossly inadequate. Difficult surgical procedures were undertaken at home, ending in cases of "failed forceps" being admitted to hospital. In one horrifying series of 100 failed forceps, 12 mothers died, 19 survived but were "morbid," and only 38 of the infants survived. ${ }^{8}$

The greatest disparity, however, was in the provision of specialist care. In the early 1930 s, for example, there were 24 consultant obstetricians in Lancashire and 10 in Birmingham. Gloucestershire had none; general practitioners who encountered a major obstetric complication called in a colleague rather than a general surgeon in Gloucester or Bristol whose experience of obstetrics was slight. ${ }^{9}$

We find the reasons for maternal mortality in the disparate, ill organised, and often poor standard of maternal care in the first 30 years of this century. The chief culprits were the teaching hospitals, where obstetrics was often a despised specialty. A derisory standard of training instilled bad habits and the low standard of obstetrics in general practice. ${ }^{10}$ Moreover, with the exception of a few notable individuals such as Dame Janet Campbell at the Ministry of Health, leadership from the top was timorous and indecisive, and funding was through local authorities, who spent as little as possible on maternal and child health.

\section{United States}

In the United States most obstetricians had no doubt whom to blame. Quite unjustly they attributed their appalling rate of maternal mortality to midwives, whom they derided as "filthy, ignorant, gin-fingering, out of the jungles of Africa, guzzling, pestiferous, vicious" and not least "un-American."1112 The main cause of high mortality was an "orgy of interference" in which operative obstetrics ran riot. ${ }^{13}$ In 1918 an obstetrician noted that "Belly-ripping has become a mania and its maniacal ravages have invaded the realm of obstetrics." 14 In 1920, DeLee of Chicago published an account of his "prophylactic forceps operation" in which full anaesthesia, delivery by forceps, and manual removal of placenta was routine for all except those who evaded his plans by a swift spontaneous delivery. ${ }^{15}$ Dr Potter of Buffalo personally delivered 1113 patients, including 920 by version and extraction and 80 by caesarean section. ${ }^{16}$

Following such examples, unskilled or semiskilled obstetricians undertook difficult surgical procedures in 
a manner described in sober and measured terms as widespread, hurried, careless, dangerous, and sometimes downright bizarre. ${ }^{1316-19}$ Referring to the famous study of maternal mortality in New York City 1930-2, George Kosmak, the editor of the American fournal of Obstetrics and Gynecology, remarked:

It is appalling to think that any man, a graduate of a hospital, would do some of the things we hear about. For example, a man does a version, tears the body away from the head, and the head is left in utero. Then he promptly does a cesarean section, with the assistance of his brother, and gets the head out. That is not an isolated instance but an example of many. ${ }^{20}$

Maternal policies in the United States were motivated by the spirit of free enterprise and private practice, a hatred of government interference, a worship of specialisation, and the need to validate obstetrics as a surgical specialty and justify high fees by surgical procedures. ${ }^{21}$ These policies had one aim: the delivery of every woman in hospital by an accredited specialist obstetrician. The decision to abolish home deliveries by midwives and general practitioners can be traced to the early 1920s. By the 1950s it had been almost completely successful. Apart from remote rural areas and certain parts of the "deep south" nearly all deliveries took place in hospital (figure 3).

\section{North west Europe}

In north west Europe, there was a long standing tradition of well trained midwives. With few exceptions, maternity hospitals were state hospitals, the staff were state employees, and rates of interference were much lower. In 1933, 20\% of all deliveries in New York City were operative, compared with $3 \cdot 2 \%$ in Sweden and less than $1 \%$ in the Netherlands. ${ }^{17}$ "It is easy to see what is the cause of high maternal mortality in the United States," said a Danish professor of obstetrics in 1929 to a visiting American expert in maternal care. "You interfere-operate too much. We give nature a chance." The visitor saw with astonishment a series of deliveries by midwives of stolid uncomplaining patients, without recourse to anaesthesia, drugs, or instruments, the "position of trust and respect in which the midwife is held in Denmark" and "the cordial relations between physicians and midwives." 22

The Netherlands and Scandinavian countrieswhere maternal mortality in the 1920 s was around 250 per 100000 births compared with 400 in England and Wales and over 700 in the USA - were aware that they had achieved the lowest maternal mortality in the world. They saw no reason to change. In these countries the midwife was the central figure in obstetric care. She was a pure midwife, not a nurse-midwife, with a higher income and status than the nurse. In the Netherlands, where most births were home births, James Young of London said midwives were trained "for a period of three years" and "better equipped with an experience in ordinary midwifery and a knowledge of the signs of danger [than] the students trained at our [British] medical schools." ${ }_{13}$ In 1926 the American obstetrician George Kosmak was equally impressed by the Swedish midwives: "Bright, healthy looking, intelligent young women from whom our best class of trained nurses would be recruited in this country."

The low maternal mortality in Scandinavia led to some speculation on racial and genetic factors. It was suggested that Scandinavian women suffered less rickets, were temperamentally more stolid, and were better built for childbirth with powerful muscles and broad pelvises through which a baby could slip easily. ${ }^{24}$ This notion was neatly scotched when it was shown that maternal mortality among recent Scandinavian immigrants in the United States was as high as that

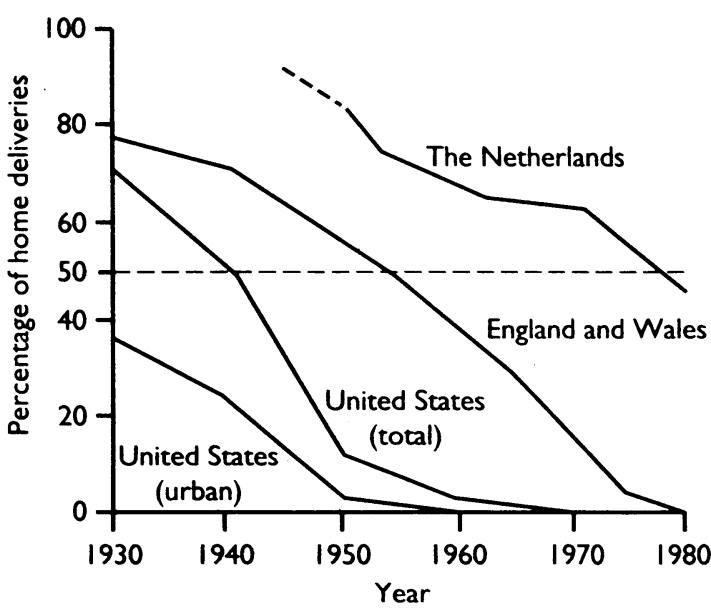

FIG 3-Home deliveries, $1930-80$

among the "native white population." 225 The system of maternal care-not a special set of favourable physical and mental attributes - enabled the women of north west Europe to be delivered with the lowest risk of dying in childbirth in the Western world.

\section{The decline in maternal mortality}

Until the mid-1930s, much the most common cause of maternal deaths was puerperal fever, mostly due to highly virulent strains of Streptococcus pyogenes ( $\beta$ haemolytic streptococcus Lancefield group A) associated with a high rate of carriers in the healthy population, especially among doctors and nurses. ${ }^{4}$ Grouped with these were deaths from septic abortion; there were no antibiotics. Nothing short of minimal interference and strict aseptic precautions of the standard employed in abdominal surgery could substantially reduce deaths due to puerperal fever, and nothing could be done for postabortive sepsis. There were two other major causes of maternal deaths: toxaemia or eclampsia, for which there were many treatments but few if any that were effective, and obstetric haemorrhage - there was virtually no blood transfusion, no ergometrine, and the standard procedure for central placenta praevia was to pass a hand through the placenta, and bring down a leg, a procedure known as "plugging with the half breech." Sepsis, toxaemia, and haemorrhage accounted for about three quarters of all maternal deaths.

Under these circumstances, only trained birth attendants who could judge accurately the progress of labour, who would wait patiently and deal efficiently with the third stage, who performed the minimum of vaginal examinations and surgical procedures, and who were as conscientious as possible in antisepsis and asepsis, could achieve levels of maternal mortality in the region of 100 deaths per 100000 births. Such levels were achieved in the 1920s by the Queen's Institute nurse-midwives in Britain and two maternity services in the United States, consisting of trained and supervised midwives who undertook home deliveries among the poor: the Kentucky Frontier Nursing Service, ${ }^{26} 27$ and a service instituted in Newark, New Jersey, by Dr Julius Levy. ${ }^{28} 29$

In all these countries for the more than $95 \%$ of normal labours or labours with only minor complications, delivery by a midwife was generally safer than delivery by a doctor, home deliveries were generally safer than hospital, and separate maternity hospitals were certainly safer than maternity units in general hospitals. ${ }^{30}$ The high maternal mortality and the differences between the countries we have considered can, I believe, be interpreted in terms of these observations. It should be added that in Britain and the United States many maternal deaths during the interwar period 
could have been prevented by simple measures based on knowledge available at the time.

Once the decline in maternal mortality had begun in the 1930s something unexpected and extraordinary occurred. By 1960 the rates of maternal mortality in the United States, England and Wales, and the Netherlands, previously so far apart, had not only fallen more steeply than anyone could have predicted: they were virtually identical (fig 2, table II) in spite of the differences in maternal care in these countries. Two things seem clear: firstly, the fact that the rate of decline was virtually constant (forming a straight line when plotted on a logarithmic scale as in figure 1) suggests there was not one or two, but a series of factors in succession; secondly, that those factors probably came into operation at approximately the same time in the countries we have discussed.

TABLE II-Maternal mortality per 100000 live births in 1920, 1940, and 1960.

\begin{tabular}{lccc}
\hline & 1920 & 1940 & 1960 \\
\hline United States & 689 & 376 & 37 \\
England and Wales & 433 & 261 & 39 \\
The Netherlands & 242 & 235 & 37
\end{tabular}

The most important factors were the sulphonamides in $1937,,^{31}$ penicillin in 1944 or 1945 , blood transfusion and ergometrine during the second world war, safe Caesarean section, and safer methods of induction for toxaemia since the $1950 \mathrm{~s}$. In addition there was probably a decline in the virulence of $S$ pyogenes and certainly a decline in septic abortion. Equally important, and in large part stemming from these advances, was the transformation of obstetrics from a minor and often pessimistic specialty in the 1930s to a major and highly optimistic one by the 1960 s, for this was the key to the development of better obstetric education, organisation of maternal care as whole, and provision of specialist services. Thus the transformation of maternal mortality was due to a large number of factors, therapeutic, educational, and administrative, which did not exist or existed in an imperfect state before 1935. As the Netherlands has shown, the move in most Western countries towards total hospital delivery was not the major factor in the transformation; it was only one way of implementing the changes I have outlined in this paper.

What must not be forgotten, however, is that this transformation has been confined to developed countries. In a recent paper, Duley reminds us that "It is now widely accepted that at least half a million women die each year of pregnancy-related causes, and that $99 \%$ of these deaths occur in the developing world." 32 In developing countries, where the distribution of maternal deaths by cause is closely similar to the distribution found in developed countries in the nineteenth century, the rate of maternal mortality is 100-200 times higher than it is in Europe and North America. "There is no other public health statistic for which the disparity between developed and developing countries is so wide. ${ }^{32}$

1 Department of Health. Report on confidential enquaries into matemal deaths in England and Wales 1982-4. London: HMSO, 1981. (Reports on health and social subjects No 34 .)

2 Tandy E. Comparability of matemal monality rates in the United States and cenain foreign countries. Washington: United States Department of Labor, 1935. (Children's Bureau publications No 229.)

3 Loudon I. Obstetric care, social chass and maternal mortality. BMF 1986;293: 606-8.

4 Loudon I. Death in childbirth. An international study of maternal care and imatermal morrality, 1800-1950. Oxford: Oxford University Press, 1992.

5 39th Report of the registrar general for 1876. London: General Register Office, 1878.242.

6 38th Report of the registrar general for 1875. London: General Register Ofice, 1877:234.

7 Loudon I. Obstetrics and the general practitioner. BMY 1990;301:703-7.

8 Crawford M. The obstetric forceps and its use. Lancet 1932;i:1239-43.
9 Public Record Office, Ministry of Health. Records of matemal and child health. MH 66/90, 91, 92 and MH 66/58, 66, 88 .

10 Baird D. The evolution of modern obstetrics. Lancet 1960;ii:557-64, 609-14.

11 Deavitt $\mathrm{N}$. The statistical case for the elimination of the midwife. Women and Health 1979;4:81-96, 169-86.

12 DeLee JB. Progress towand ideal obstetrics. Am 7 Obstet 1916;73:407-15.

13 Young J. Maternal mortality and maternal mortality rates. Am $f$ Obstet Gymecol 936;31:198-212.

14 Findley P. The lost art of obstetrics. Northevest Medicine 1918:17:67-70.

15 DeLee JB. The prophylactic forceps operation. Am J Obstet Gymecol 1920-21;1:34-44, 77-84.

16 Whitridge Williams $\mathrm{J}$. A criticism of certain tendencies in American obstetrics. N Y State f Med 1992;22:493-9.

17 New York Academy of Medicine and New York City Public Health Commitree. Matemal moralizy in New York City, 1930, 1931, 1932. New York: The Commonwealth Fund, 1933.

18 White House Conference on Child Health Protection. Fetal, newborn and matemal morbidity and mortality. New York: Appleton-Century, 1933.

19 Maternal deaths. A brief report of a study made in fifteen states. Washington: United States Department of Labor, 1933. (Children's Bureau publication No 221.)

20 Porges RF. The response of the New York Obstetrical Society to the report by the New York Academy of Modicine on maternal mortality, 1933-4. Obstet Gymecol 1985; 152:642-9.

21 Medical and nursing services for the maternal cases of the National Health Survey. Public Health Repors 1941;56:855-6.

22 Mendenhall D. Midwifery in Dermark. Washington: United States Department of Labor, Children's Bureau, 1929.

23 Kosmak GW. Results of supervised midwife practice in certain European countries. Can we draw a lesson from this for the United States? fAMA 1927;89:2009-12.

24 Ministry of Health. Final report of Departmental Committee on Maternal Mortality and Morbidity. London: HMSO, 1932.

25 Woodbury RM. Matemal mornality. Washington DC: United States Department of Labor, 1926. (Children's Bureau publication No 152. )

26 Breckinridge M. The nurse-midwife. A pioneer. Am $\mathcal{Y}$ Public Health 1927;17:1141-51.

27 Breckinridge M. Wide neighborhoods. Lexington, Kentucky: University. Press of Kentucky; 1981.

28 Levy J. The maternal and infant mortality in midwifery practice in Newark, NJ. Am $\mathcal{O}$ Obstet 1918;77:41-53.

29 Levy J. Maternal mortality and mortality in the first month of life in relation to attendant at birth. Amer $\mathcal{F}$ Public Health 1923;13:88-95.

30 DeLee JB, Siedentopf $\mathrm{H}$. The maternity ward of the general hospital. JAMA 1933;100:6-14.

31 Loudon I. Puerperal fever, the streptococcus and the sulphonamides, 1911 1945. BMF 1987;295:485-90.

32 Duley L. Maternal mortality associated with hypertensive disorders of pregnancy in Africa, Asia, Latin America and the Caribbean. Br $\mathcal{f}$ Obste Gymaecol 1992;99:547-53.

\section{Christmas competition}

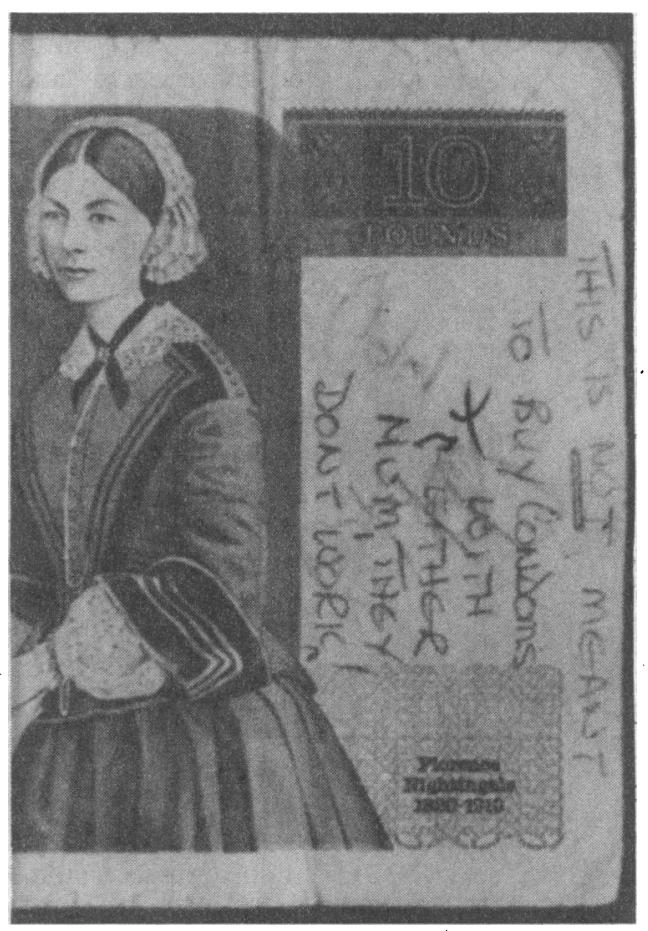

This $£ 10$ note was obtained from a building society in Durham. What are the family dynamics behind the message written on it? $A$ $B M \mathcal{F}$ teeshirt (large size only, value $£ 10$ ) is offered for the best solution. Entries to Editor, $B M \mathcal{B}$, by 15 January. Editor's decision is final. 